\title{
Purification of Drinking Water by Application of High Voltage Electric Pulses Generated from Boost Converter and Voltage Multipliers
}

\author{
Sheetal Bhat $\mathrm{B}^{1}$, Raghavendra Prabhu ${ }^{2}$ \\ PG Scholar, Electrical and Electronics Engg., NMAM Institute of Technology, Nitte, India ${ }^{1}$ \\ Assistant Professor, Electrical and Electronics Engg., NMAM Institute of Technology, Nitte, India ${ }^{2}$
}

\begin{abstract}
Drinking water can be purified by application of electric pulses across the water sample that has to be treated. Application of high Pulsed Electric Field (PEF) to the water kills the germs and the bacteria present and thus purify it. In this paper, a high voltage electric pulse generator module is proposed, which consists of boost converter and a capacitor diode voltage multiplier (CDVM) with a closed loop control on its output voltage. A low voltage DC source is used at the input and the output of the module will be a pulsed output voltage. The proposed generator is validated by simulation study.
\end{abstract}

Keywords: Pulsed Electric field, Capacitor Diode Voltage Multiplier, Boost Converter, Closed Loop Control.

\section{INTRODUCTION}

When Pulsed Electric Field (PEF) is applied to the water sample which has to be purified; PEF is one of the efficient methods present to purify water [1] an irreversible permeabilisation of the cell membrane takes place [2] which ensures killing of germs in drinking water. To avoid electrolysis of the electrodes in the treatment chamber PEF is used instead of continuous electric field $[3,4]$.

For the purification of water duration of the pulses in the pulsed electric field can be ranged from few tens of nanoseconds to few tens of microseconds [5], with a voltage level up to $50 \mathrm{kV} / \mathrm{cm}$ to cause irreversible permeabilisation of the cell membrane.

A DC-DC Boost converter is used for producing high pulsed output voltage [6]. CDVMs are used with boost converter to get a high voltage gain [7]. The CDVMs have small size and weight and high efficiency [8].

\section{PROPOSED HIGH VOLTAGE ELECTRIC PULSE GENERATOR}

\section{A. Circuit Configuration}

The high voltage electric pulse generator is shown in the Fig 1. The module is fed from a DC source. An IGBT is used to chop the generated DC voltage with a desired rate. The IGBT used is a high voltage controlled switch which is rated at output voltage of the module. The output DC voltage will have a voltage magnitude of $V_{\text {out }}$ and duration of the pulses will be equal to the turn on time of the IGBT, $S_{i}$. The frequency of the generated pulses is $\left(1 / T^{*}\right)$, where $T^{*}$ is the periodic time of the gate pulses of the
IGBT switch which equals $T_{o n}^{*} / D_{0}$, where $D_{0}$ is the duty cycle of the gate pulses of the IGBT $\left(D_{0}=T_{o n}^{*} / T^{*}\right)$. A diode is connected across the output of the module to bypass the module during deactivation/ fault module.

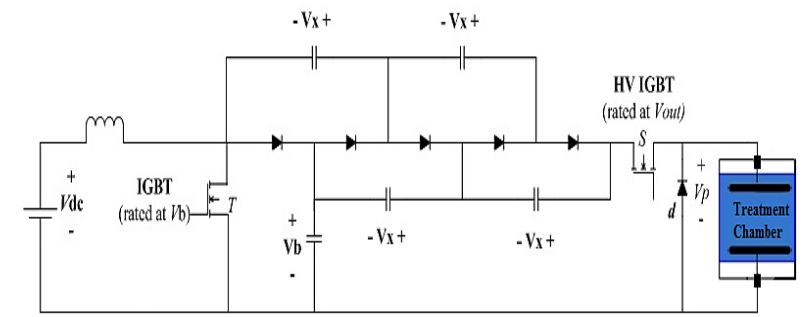

Fig.1.Construction of the Proposed High Voltage Electric Pulse Generator.

The construction of module is showed in Fig. 1. The module has a boost converter whose output voltage is regulated. The output voltage of the module $\left(\mathrm{V}_{\text {out }}\right)$ is compared with its reference value and the corresponding voltage error is fed to the Proportional Integral controller (PI controller) to generate the boost converter duty cycle ( $D_{b}$ ). The generated duty cycle is then compared with a high frequency triangular wave to generate gate pulses for the controlled switch of the boost converter (T).

B. Number of CDVM stages

Based on Fig.2, the output voltage of the module, $V_{\text {out }}$, is given by (1);

$$
V_{\text {out }}=V_{b}+m V_{x}(1)
$$




\section{National Conference on Advances in Electrical Engineering \\ NMAM Institute of Technology, Nitte \\ Vol. 5, Special Issue 2, April 2017}

Where $V_{b}$ is the output voltage of boost converter, $m$ is the number of CDVM stages, and $V_{x}$ is the voltage of each capacitor in CDVM. The voltage of each multiplier stage $A$. is given by (2);

$$
V_{x}=V_{b}(2)
$$

Then, the output voltage of each module, $V_{\text {out }}$ is given by (3);

$$
V_{\text {out }}=(m+1) V_{b}(3)
$$

The relation between boost converter output voltage, $V_{b}$, and the input DC voltage is given by (4);

$$
V_{b}=\left(\frac{1}{1-D_{b}}\right) V_{d c}(4)
$$

Where $D_{b}$ is the duty cycle of boost converter. Substituting from (4) into (3) yields (5).

$$
V_{\text {out }}=\left(\frac{m+1}{1-D_{b}}\right) V_{d c}(5)
$$

Equation (5) can be used to find the expression of $D_{b}$ in terms of the number of voltage multiplier stages $(m)$, the desired output voltage, and the given input DC voltage as in (6);

$$
D_{b}=1-\left((m+1) \frac{V_{d c}}{V_{\text {out }}}\right)(6)
$$

Equation (6) is used to choose the required number of voltage multiplier stages, $m$, to ensure operation within a moderate range of converter duty cycles.

TABLE I Relation Between Number of Stages and Duty

\begin{tabular}{|c|c|c|c|c|c|}
\hline $\mathrm{m}$ & 1 & 2 & 3 & 4 & 5 \\
\hline $\mathrm{D}_{\mathrm{b}}$ & 0.8 & 0.7 & 0.6 & 0.5 & 0.4 \\
\hline
\end{tabular}

\section{Capacitor Diode Voltage Multipliers (CDVM)}

Voltage multipliers are AC-to-DC power conversion devices, consisting of diodes and capacitors that produce a high DC voltage from a low voltage AC source. Multipliers are made up of multiple stages. Assembly type used here is Half-wave Parallel Multiplier, Fig.2.

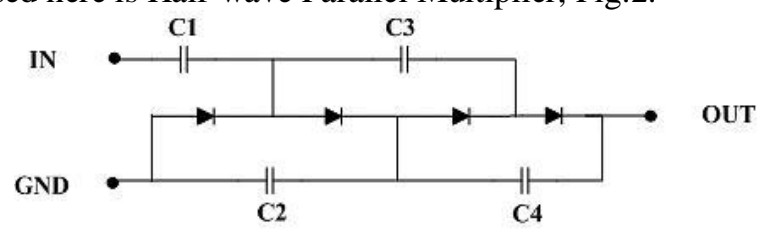

Fig.2. CDVM Schematic.

Its characteristics are:

1) Small size

2) Highly efficient

3) Uniform stress on diodes

4) Increasing voltage stress on capacitors with successive stages

\section{DESIGN OF MODULES}

A. Selection of Boost Converter Inductor Equivalent resistance of the switched load and the equivalent resistance seen by the boost converter output are

$$
\begin{aligned}
& R_{e q}=\frac{R_{\text {Load }}}{D_{0}}=\frac{T^{*} R_{\text {Load }}}{T_{o n}^{*}}(7 \mathrm{a}) \\
& R_{b}=R_{\text {eq }}\left(\frac{V_{b}}{V_{\text {out }}}\right)^{2}=\frac{R_{\text {Load }}}{D_{0}}\left(\frac{V_{b}}{V_{\text {out }}}\right)^{2}(7 \mathrm{~b})
\end{aligned}
$$

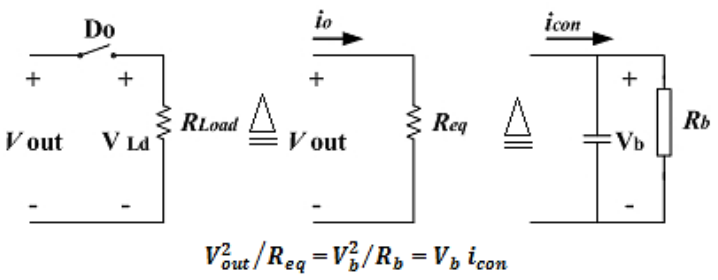

Fig.3.Equivalent Resistances.

Continuous current mode with low current ripple is used so that the inductor core losses reduced. The selected inductance should be greater than the critical inductance to ensure the above condition.

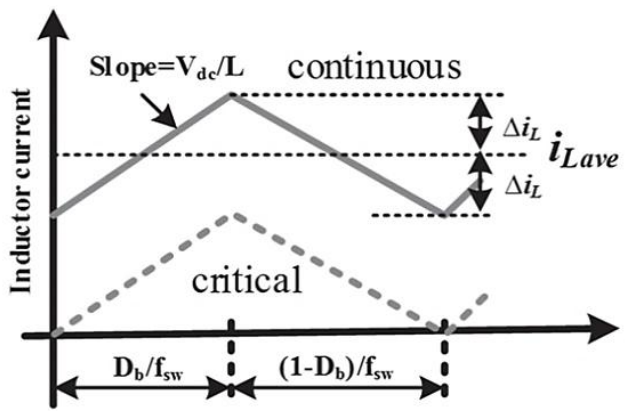

Fig.4.Steady State Variation of the Inductor Current.

From Fig.4, the ripple current through the inductor during the continuous current mode is given by (8);

$$
\Delta i_{L}=\frac{D_{b} V_{d c}}{2 L f_{s w}}(8)
$$

During the critical condition mode, the ripple current will be equal to the average inductor current. Hence the critical inductance will be calculated from (9);

$$
L_{\text {critical }}=\frac{D_{b} V_{d c}}{2 i_{L \text { ave }} f_{s w}}(9)
$$

Based on Fig.3, the average conductor current is given by (10);

$$
i_{L \text { ave }}=\frac{i_{c o n}}{1-D_{b}}=\frac{\left(V_{\text {out }}^{2} /\left(V_{b} R_{e q}\right)\right.}{1-D_{b}}(10)
$$

Where $i_{c o n}$ is the boost converter output current, then the critical inductance, $L_{\text {critical }}$ is given by substituting (7a) and (10) in (9)

$$
\mathrm{L}_{\text {critical }}=\frac{\mathrm{D}_{\mathrm{b}}\left(1-\mathrm{D}_{\mathrm{b}}\right) \mathrm{R}_{\mathrm{Load}} \mathrm{V}_{\mathrm{dc}} \mathrm{V}_{\mathrm{b}}}{2 \mathrm{D}_{0}\left(\mathrm{~V}_{\text {out }}^{2}\right) \mathrm{f}_{\mathrm{sw}}}(11)
$$




\title{
International Journal of Innovative Research in Electrical, Electronics, Instrumentation and Control Engineering
}

NCAEE 2017

\author{
National Conference on Advances in Electrical Engineering \\ NMAM Institute of Technology, Nitte
}

Vol. 5, Special Issue 2, April 2017

B. Selection of Capacitors Used in the Module

All the capacitors in the module are assumed equal. The capacitance is chosen to ensure acceptable output voltage ripple.

$$
\frac{\Delta v_{b}}{V_{b}}=\frac{D_{b}}{f_{s w} R_{b} C_{m}}(12)
$$

Equation (7b) is substituted in (12) and the expression for capacitance is obtained as (13).

$$
\mathrm{C}_{\mathrm{m}}=\frac{\mathrm{D}_{\mathrm{b}} \mathrm{D}_{0} \mathrm{~V}_{\text {out }}^{2}}{\mathrm{f}_{\mathrm{sw}} \mathrm{R}_{\text {Load }} \Delta \mathrm{v}_{\mathrm{b}} \mathrm{V}_{\mathrm{b}}}(13)
$$

\section{Numerical Example}

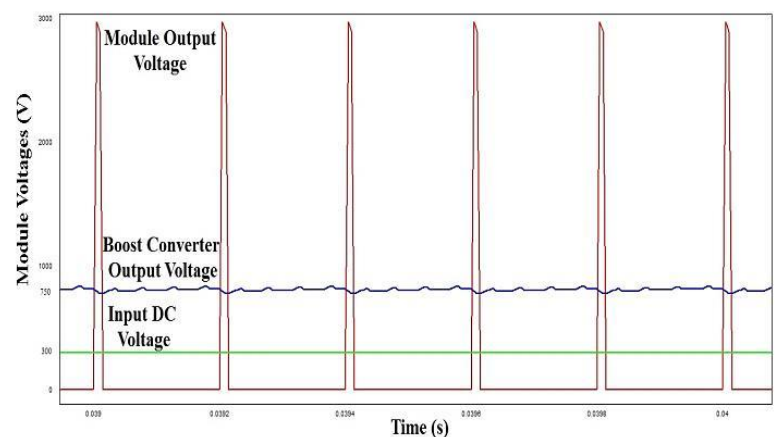

Fig.5. Module Voltages.

Fig.6. shows the inductor current flowing through the module. The inductor current here is continuous.Fig.7. shows the CDVM capacitor voltages. It is clear that the capacitors and the diodes have relatively low voltage rating of $1 \mathrm{kV}$. as $1 \mathrm{k} \Omega$

- $\quad$ From (6), the relation between boost converter duty cycle and the CDVM stages is given by

$$
\mathrm{D}_{\mathrm{b}}=1-\left((\mathrm{m}+1) \frac{300}{3000}\right)=0.1(9-\mathrm{m})
$$

For $\mathrm{m}=3$, the duty cycle of the boost converter will be 0.6 .

- From (4), The output voltage of the boost converter will be

$$
\mathrm{V}_{\mathrm{b}}=\left(\frac{1}{1-\mathrm{D}_{\mathrm{b}}}\right) \mathrm{V}_{\mathrm{dc}}=\left(\frac{1}{1-0.6}\right) 300=750 \mathrm{~V}
$$

- The switching frequency of the boost converter is selected as $20 \mathrm{kHz}$, then the critical inductance of the boost converter can be obtained from (11).

$$
\begin{aligned}
& L_{\text {critical }}=\frac{D_{b}\left(1-D_{b}\right) R_{L o a d} V_{d c} V_{b}}{2 D_{0}\left(V_{\text {out }}^{2}\right) f_{s w}} \\
= & \frac{0.6(1-0.6)(1000)(300)(750)}{2(0.05)\left(3000^{2}\right)(20000)}=3 \mathrm{mH}
\end{aligned}
$$

- The capacitor voltage ripple is taken as $3 \%$, the capacitance of the capacitors present in the module will be

$$
\begin{gathered}
C_{m}=\frac{D_{b} D_{0} V_{\text {out }}^{2}}{f_{s w} R_{\text {Load }} \Delta v_{b} V_{b}} \\
=\frac{(0.6)(0.05)\left(3000^{2}\right)}{(2000)(1000)(0.03 * 750)(750)}=0.8 \mu F
\end{gathered}
$$

- The duty cycle of the output voltage which is in form of pulses will be,

$$
\mathrm{D}_{0}=\frac{\mathrm{T}_{\mathrm{on}}^{*}}{\mathrm{~T}^{*}}=\frac{10 \times 10^{-6}}{1 / 5000}=0.05
$$

\section{SIMULATION}

A software simulation model has been built for the high electric pulse generator with the data as mentioned in the numerical example. The corresponding simulation results are shown in the figures below. A well regulated output voltage of the module is obtained.

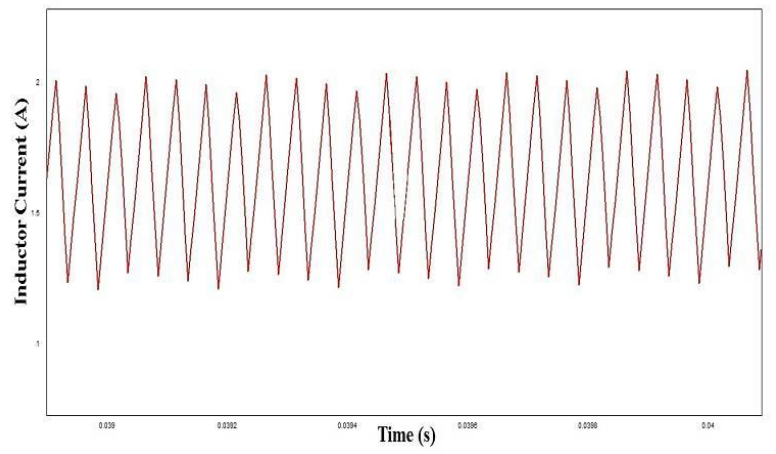

Fig.6. Boost Converter Inductor Current.

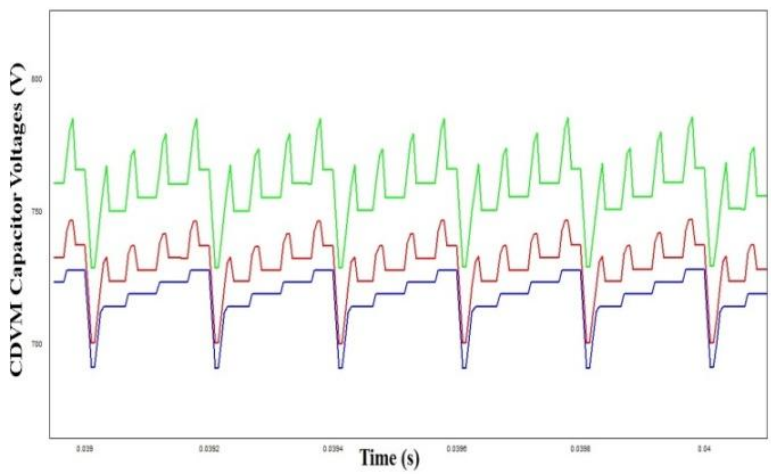

Fig.7. CDVM Capacitor Voltages.

\section{IV.CONCLUSION}

In this paper, a high voltage electric pulse generator has been proposed for purification of water. The module of the proposed pulse generator is fed from a low voltage DC source, and has a boost converter with a capacitor- diode voltage multiplier (CDVM). The proposed generator provides high voltage pulses using low/ medium voltage components. In the output stage a controlled switch is 
Vol. 5, Special Issue 2, April 2017

needed to chop the output voltage with desired width and rate. The pulsed output voltage is connected to high voltage electrodes and applied across the water sample which has to be purified, so that the generated PEF kills the germs and bacteria present in water. Finally, simulation validation has been done to confirm the viability of the proposed approach.

\section{ACKNOWLEDGMENT}

Authors gratefully acknowledge the support received from R\&D Centre, Nitte, NMAM Institute of technology, Nitte Education Trust and VTU, Belagavi in carrying out the research work.

\section{REFERENCES}

[1] Ahmed Elserougi and Shehab Ahmed, Ahmed Massoud, "Multimodule High Voltage Generator Based on DC-DC Boost Converter and CDVMs for Drinking Water Purification", IEEE International Conference on Industrial Technology (ICIT), pp. 334-338, 2016.

[2] A. Abou-Ghazala, S. Katsuki, Karl H. Schoenbach, F. C. Dobbs, and K. R. Moreira, "Bacterial Decontamination of Water by Means of Pulsed- Corona Discharges" IEEE Transactions on Plasma Science, vol. 30, no. 4, pp.1449-1453,2002.

[3] P T Johnstone and P S Bodger, "High Voltage Disinfection of Liquids" IPENZ Transactions, vol. 24, no. 1, 1997.

[4] Karl H. Schoenbach, Frank E. Peterkin, Raymond W. Alden, and Stephen J. Beebe "The Effect of Pulsed Electric Fields on Biological Cells: Experiments and Applications", IEEE Transactions on Plasma Science, vol. 25, no. 2, pp. $284-292$, 1997.

[5] ZikangYang,LanXiong, Xiaojie Ye, Bo Long, Zhaohui Xi , and Wei He "High Voltage Pulse Generator Based on Marx Circuit and its Application for Sterilization", 3rd International Conference on Biomedical Engineering and Informatics (BMEI), vol. 3, pp. 1310 1314,2010.

[6] S. Zabihi, F. Zare, G. Ledwich, A. Ghosh, and H. Akiyama, "A Novel High-Voltage Pulsed-Power Supply Based on Low-Voltage Switch- Capacitor Units", IEEE Transactions on Plasma Science, vol. 38 , no. 10 , pp. $2877-2887,2010$.

[7] J.C. Rosas-Caro, J.M. Ramirez, F.Z. Peng, and A. Valderrabano, "A DC-DC multilevel boost converter", IET Power Electron., vol. 3, no. 1, pp. 129-137, 2010.

[8] L. M. Redondo, "A DC Voltage-Multiplier Circuit Working as a High- Voltage Pulse Generator", IEEE Transactions on Plasma Science, vol. 38, no. 10, pp. 2725-2729,2010. 